\title{
$\mathrm{ZnO} / \mathrm{Ag} / \mathrm{SnO}_{2}$ 적층박막의 두께 변화에 따른 전기적, 광학적 특성 연구
}

\author{
김유성 · 최진영 · 박윤제 · 최수현 · 공영민 · 김대일* \\ 울산대학교 첨단소재공학부
}

\section{Influence of Film Thickness on the Electrical and Optical Properties of $\mathrm{ZnO} / \mathrm{Ag} / \mathrm{SnO}_{2}$ Tri-Layer Films}

\author{
Yu-Sung Kim, Jin-Young Choi, Yun-Je Park, Su-Hyeon Choe, Young-Min Kong, and Daeil Kim* \\ School of Materials Science and Engineering, University of Ulsan, Ulsan 44610, Republic of Korea
}

\begin{abstract}
ZnO} / \mathrm{Ag} / \mathrm{SnO}_{2}$ (ZAS) tri-layer films were prepared on glass substrates via $\mathrm{RF}$ and $\mathrm{DC}$ magnetron sputtering, and then the influence of the thickness of the $\mathrm{ZnO}$ and $\mathrm{SnO}_{2}$ layers on the optical and electrical properties of the ZAS films was investigated. As deposited $\mathrm{ZnO} 50 \mathrm{~nm} / \mathrm{Ag} 10 \mathrm{~nm} / \mathrm{SnO}_{2} 50 \mathrm{~nm}$ films showed a higher figure of merit, $1.08 \times 10^{-2} \Omega^{-1}$, than the other films due to a high visible transmittance of $80.8 \%$ and a low resistivity of $1.21 \times 10^{-4} \Omega \mathrm{cm}$. From the observed results, it can be concluded that the $\mathrm{ZnO} 50 \mathrm{~nm} / \mathrm{Ag}$ $10 \mathrm{~nm} / \mathrm{SnO}_{2} 50 \mathrm{~nm}$ tri-layer films can be used as a substitute for conventional transparent conducting oxide films in various opto-electrical applications.
\end{abstract}

(Received March 20, 2019; Accepted April 4, 2019)

Keywords: $\mathrm{ZnO} / \mathrm{Ag} / \mathrm{SnO}_{2}$, thin film, x-ray diffraction, electrical properties, optical properties.

\section{1. 서 론}

인듐-주석산화물( $\mathrm{Sn}$ doped $\mathrm{In}_{2} \mathrm{O}_{3}$; ITO)을 포함한 투명전 도성 산화물 (Transparent Conducting Oxide, TCO) 박막 은 높은 가시광 투과도 $(\geq 80 \%)$ 와 낮은 면저항 $(\leq 100 \Omega / \mathrm{cm})$ 특성을 동시에 갖기 때문에 마그네트론 스퍼터(Magnetron sputter) 와 같은 물리적 기상 증착(Physical Vapor Deposition, $\mathrm{PVD}$ ) 장치로 증착되어 다양한 표시소자 (Display device) 와 태양전지(Solar cells), 저방사유리 (Low emissivity glass)등의 전자 재료 및 친환경 에너지소재에 활용되고 있 다 $[1,2]$. 최근에는 다양한 전자재료 산업의 발전과 더불어 기존 ITO 박막보다 가격경쟁력과 화학적 안정성이 보고된 $\mathrm{ZnO}$ 에 미량의 $\mathrm{Ga}$ 이 첨가된 $\mathrm{GZO}$ 박막이 $\mathrm{In}_{2} \mathrm{O}_{3}$ 의 효율적 인 대체재로 개발되었다 [3]. 또한 S. Kim 은 가볍고 외 부충격에도 강한 폴리-카보네이트 (Poly-carbonate) 기판에 $\mathrm{GZO} / \mathrm{TiO}_{2}$ 적층박막을 $\mathrm{RF}$ 마그네트론 스퍼터로 증착하고 전자빔 표면조사를 통하여 전기적, 광학적 특성을 개선한

- 김유성: 박사과정, 최진영·박윤제·최수현: 석사과정, 공영민·김대일: 교수 *Corresponding Author: Daeil Kim

[Tel: +82-52-712-8066, E-mail: dkim84@ulsan.ac.kr]

Copyright (c) The Korean Institute of Metals and Materials
저온 표면개질 기술을 발표하였다 [4]. 그러나 일반적으로 상온에서 증착된 투명전도성 $\mathrm{TCO}$ 박막은 표시소자용 투 명전극으로 사용하기에는 부족한 전기전도도 및 가시광투 과율을 갖기 때문에 증착 중 기판온도 또는 증착 후 열처 리온도를 최적화하여 전기광학적 특성을 개선하고 있다 [5]. 본 연구에서는 유연성 표시소자 (Flexible display device)에 적합한 투명전극용 박막을 개발하기 위하여 별 도의 열처리 없이 기존의 ITO 특성에 비교될 $\mathrm{TCO} / \mathrm{metal} /$ $\mathrm{TCO}(\mathrm{OMO})$ 구조인 $\mathrm{ZnO} / \mathrm{Ag} / \mathrm{SnO}_{2}(\mathrm{ZAS})$ 박막을 증착하고 하부 $\mathrm{ZnO}$ 박막과 상부 $\mathrm{SnO}_{2}$ 박막의 두께변화에 따른 전 기적, 광학적 특성을 고찰하여 효과적인 ZAS 박막의 적층 구조를 제안하였다.

\section{2. 실험 방법}

본 연구에서는 상온에서 크기(3 Inch)가 동일한 $\mathrm{ZnO}$ 와 $\mathrm{SnO}_{2}$ (순도 $99.99 \%$ ) 타겟과 $\mathrm{Ag}(3 \mathrm{Inch}$, 순도 $99.95 \%$ ) 타겟이 장착된 $\mathrm{RF}$ 와 $\mathrm{DC}$ 마그네트론 스퍼터를 이용하여 유리기판에 서로 다른 적층형태를 갖는 $\mathrm{ZnO} / \mathrm{Ag} / \mathrm{SnO}_{2}$ 박 막을 증착하였다. 유리기판(Corning 1797, $3 \times 3 \mathrm{~cm}^{2}$ )은 메 탄올, 증류수의 순서로 초음파 세척을 실시하고 질소가스 
Table 1. Experimental condition of $\mathrm{ZnO}, \mathrm{SnO}_{2}$ single layer and $\mathrm{ZnO} / \mathrm{Ag} / \mathrm{SnO}_{2}$ tri-layer deposition.

\begin{tabular}{|c|c|}
\hline Base pressure (Torr) & $7.0 \times 10^{-7}$ \\
\hline Deposition pressure (Torr) & $1.0 \times 10^{-3}$ \\
\hline $\mathrm{ZnO}, \mathrm{SnO}_{2} \quad \mathrm{RF}$ Power $\left(\mathrm{W} / \mathrm{cm}^{2}\right)$ & 2.5 \\
\hline DC Power $\left(\mathrm{W} / \mathrm{cm}^{2}\right)$ & 2.0 \\
\hline Ar gas flow rate $(\mathrm{sccm})$ & $\mathrm{SnO}_{2}, \mathrm{Ag}: 10$ \\
\hline \multicolumn{2}{|l|}{ Thickness (nm) } \\
\hline $\mathrm{ZnO}, \mathrm{SnO}_{2}$ single layer & 100,100 \\
\hline $\mathrm{ZnO} / \mathrm{Ag} / \mathrm{SnO}_{2}$ tri-layer & $30 / 10 / 70,50 / 10 / 50,70 / 10 / 30$, \\
\hline \multicolumn{2}{|l|}{ Deposition rate $(\mathrm{nm} / \mathrm{min})$} \\
\hline $\mathrm{ZnO} / \mathrm{Ag} / \mathrm{SnO}_{2}$ & $3.0 / 6.0 / 4.4$ \\
\hline
\end{tabular}

로 건조하였으며, 타겟과 기판의 거리는 $6 \mathrm{~cm}$ 로 고정하였 다. 자세한 증착조건은 표 1 에 나타내었다. 증착 후, 단차 측정기(Dektak-150, Varian)을 사용하여 박막의 두께와 증 착율을 계측하였고, 박막의 두께변화에 따른 가시광 투과 율은 자외선-가시광 분광기 (UV-visible spectrophotometer, 측정영역 300-800 nm, Cary 100 Cone, Varian, 기초과 학지원연구원, KBSI 대구센터)로 측정하였으며, 기판의 평 균 가시광투과율은 $91 \%$ 를 유지하였다. 적층박막의 Root mean square(RMS) 표면거칠기 분석은 원자간력현미경 (Atomic force microscope, XE-100, Park system)을 이 용하였고, 전기적 특성은 Van der Pauw 법을 적용한 Hall효과 측정기 (HMS-3000, Ecopia)로 측정하였다. 효율 적인 $\mathrm{ZnO} / \mathrm{Ag} / \mathrm{SnO}_{2}$ 박막의 적층두께를 제안하기 위하여 박막의 Figure or merit[5] 수치를 비교하고 검토하였다.

\section{3. 결과 및 고찰}

$\mathrm{ZnO}, \mathrm{SnO}_{2}$ 단층박막과 $\mathrm{ZnO} / \mathrm{Ag} / \mathrm{SnO}_{2}$ 적층박막의 두께 에 따른 $\mathrm{X}$ 선 회절패턴 (X-ray diffraction pattern)과 결정 립 크기(Crystallite size) 변화를 Scherer 관계식을 이용하 여 그림 1과 표 2에 나타내었다[6]. $\mathrm{ZnO}$ 단층박막이 가장 높은 Intensity Peak와 가장 좁은 반가폭 수치(Full width at half maximum, FWHM)를 보이며 $7.7 \mathrm{~nm}$ 크기의 결 정립을 보였으며, $\mathrm{ZnO}$ 박막층이 얇아질수록 결정립의 크 기는 감소하였고, $\mathrm{SnO}_{2}$ 단층박막은 전형적인 비정질상의 회절패턴을 보였다.

투명전극용 박막의 높은 표면조도(Surface roughness 거 칠기)는 전하이동도 감소로 인한 비저항 증가와 가시광의 표면흡수 및 산란에 따른 가시광투과율 감소의 직접적인 원인이 되므로 투명전극용 박막의 표면조도는 전기광학적 특성 최적화에 핵심적인 요소이다. 그림 2 는 $\mathrm{ZnO}$ 와 $\mathrm{SnO}_{2}$

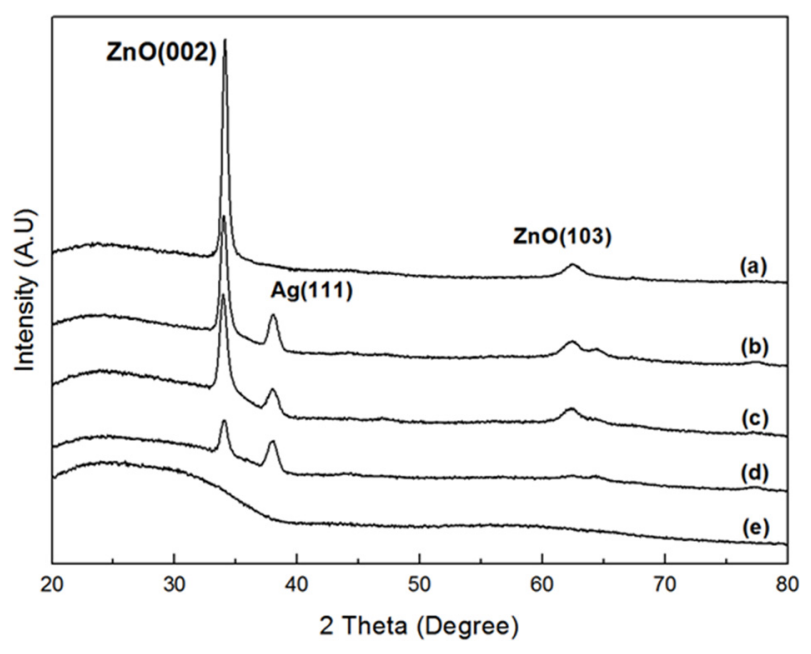

Fig. 1. $\mathrm{XRD}$ diffraction pattern of $\mathrm{ZnO}, \mathrm{SnO}_{2}$ single layer and $\mathrm{ZnO} /$ $\mathrm{Ag} / \mathrm{SnO}_{2}$ (ZAS) tri-layer films. (a) $\mathrm{ZnO} 100 \mathrm{~nm}$, (b) $\mathrm{ZnO} 70 \mathrm{~nm} / \mathrm{Ag}$ $10 \mathrm{~nm} / \mathrm{SnO}_{2} 30 \mathrm{~nm}$, (c) $\mathrm{ZnO} 50 \mathrm{~nm} / \mathrm{Ag} 10 \mathrm{~nm} / \mathrm{SnO}_{2} 50 \mathrm{~nm}$, (d) $\mathrm{ZnO}$ $30 \mathrm{~nm} / \mathrm{Ag} 10 \mathrm{~nm} / \mathrm{SnO}_{2} 70 \mathrm{~nm}$, (e) $\mathrm{SnO}_{2} 100 \mathrm{~nm}$.

Table 2. Comparison of grain size of $\mathrm{ZnO}(002)$ on the $\mathrm{ZnO}$ single layer and $\mathrm{ZnO} / \mathrm{Ag} / \mathrm{SnO}_{2}$ (ZAS) tri-layer films.

\begin{tabular}{ccccc}
\hline $\begin{array}{c}\text { Thickness } \\
(\mathrm{nm})\end{array}$ & $\begin{array}{c}\text { 2 Theta } \\
(\text { degree })\end{array}$ & $\begin{array}{c}\text { FWHM } \\
(\text { degree })\end{array}$ & $\begin{array}{c}\text { Grain size } \\
(\mathrm{nm})\end{array}$ \\
\hline \multicolumn{2}{c}{ ZnO single layer } & 34.1 & 0.52 & 16.1 \\
\hline \multirow{2}{*}{ ZAS } & $70 / 10 / 30$ & 34.0 & 0.54 & 15.3 \\
tri-layer & $50 / 10 / 50$ & 33.9 & 0.58 & 14.3 \\
& $30 / 10 / 70$ & 34.0 & 0.64 & 12.9 \\
\hline
\end{tabular}

박막의 두께변화에 따른 $\mathrm{ZnO} / \mathrm{Ag} / \mathrm{SnO}_{2}$ 박막의 표면거칠기 측정 결과이다. $\mathrm{ZnO}$ 와 $\mathrm{SnO}_{2}$ 단층박막의 거칠기는 각각 $4.28 \mathrm{~nm}$ 와 $1.12 \mathrm{~nm}$ 이었으며, $\mathrm{ZnO} 50 \mathrm{~nm} / \mathrm{Ag} 10 \mathrm{~nm} / \mathrm{SnO}_{2}$ $50 \mathrm{~nm}$ 박막은 $2.2 \mathrm{~nm}$ 의 평균거칠기를 보였다. 이는 그림 1 의 $\mathrm{X}$ 선 회절패턴 과 표 2의 결정립크기(Crystallite size) 에서 나타난 결과와 같이 결정화로 인하여 가장 높은 $\mathrm{RMS}$ 거칠기가 $\mathrm{ZnO}$ 단층박막에서 측정되었으며, 비정질상 인 $\mathrm{SnO}_{2}$ 단층박막이 상대적으로 평탄한 $\mathrm{RMS}$ 거칠기를 보였다.

그림 3 은 $\mathrm{ZnO}, \mathrm{SnO}_{2}$ 단층박막과 $\mathrm{ZnO} / \mathrm{Ag} / \mathrm{SnO}_{2}$ 적층박 막의 두께에 따른 박막의 가시광투과도 $(380-780 \mathrm{~nm})$ 를 비 교한 것이다. 유리기판과 $\mathrm{ZnO}, \mathrm{SnO}_{2}$ 단층 박막의 가시광 투과도는 각각 $90.3,83.7,81.8 \%$ 였으며 $\mathrm{ZnO} / \mathrm{Ag} / \mathrm{SnO}_{2}$ 적층박막에서는 $\mathrm{ZnO} 50 \mathrm{~nm} / \mathrm{Ag} 10 \mathrm{~nm} / \mathrm{SnO}_{2} 50 \mathrm{~nm}$ 박막 의 평균투과율이 $80.8 \%$ 로서, $\mathrm{ZnO}$ 와 $\mathrm{SnO}_{2}$ 박막의 두께 가 동일한 $50 \mathrm{~nm}$ 조건에서 상대적으로 높은 가시광투과율 을 보였다. 물론 $\mathrm{ZnO} 50 \mathrm{~nm} / \mathrm{Ag} 10 \mathrm{~nm} / \mathrm{SnO}_{2} 50 \mathrm{~nm}$ 박 막의 평균투과율이 $\mathrm{ZnO}$ 와 $\mathrm{SnO}_{2}$ 단층박막의 가시광투과도 

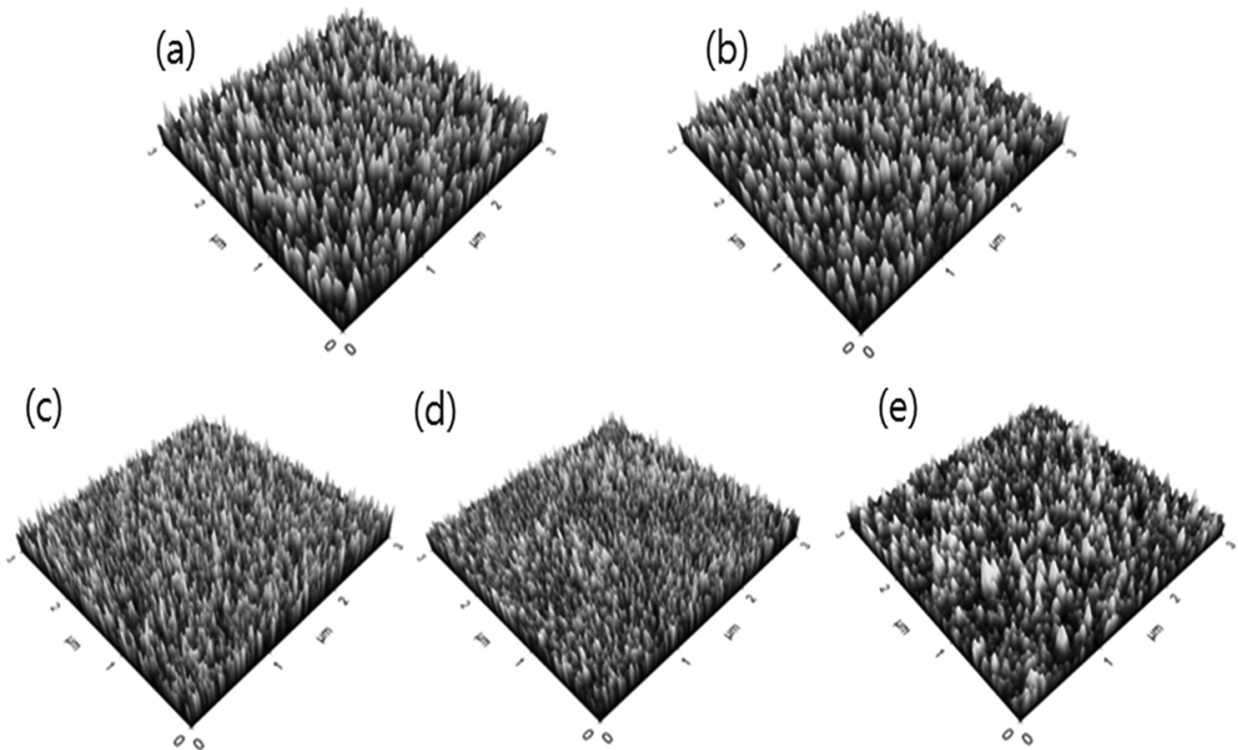

Fig. 2. AFM images and RMS roughness of the films. (a) $\mathrm{ZnO} 100 \mathrm{~nm}: 4.2 \mathrm{~nm}$, (b) $\mathrm{ZnO} 70 \mathrm{~nm} / \mathrm{Ag} 10 \mathrm{~nm} / \mathrm{SnO}_{2} 30 \mathrm{~nm}: 3.8 \mathrm{~nm}$, (c) $\mathrm{ZnO} 50$ $\mathrm{nm} / \mathrm{Ag} 10 \mathrm{~nm} / \mathrm{SnO}_{2} 50 \mathrm{~nm}: 2.2 \mathrm{~nm}$, (d) $\mathrm{ZnO} 30 \mathrm{~nm} / \mathrm{Ag} 10 \mathrm{~nm} / \mathrm{SnO}_{2} 70 \mathrm{~nm}: 1.7 \mathrm{~nm}$, (e) $\mathrm{SnO}_{2} 100 \mathrm{~nm}: 1.1 \mathrm{~nm}$.

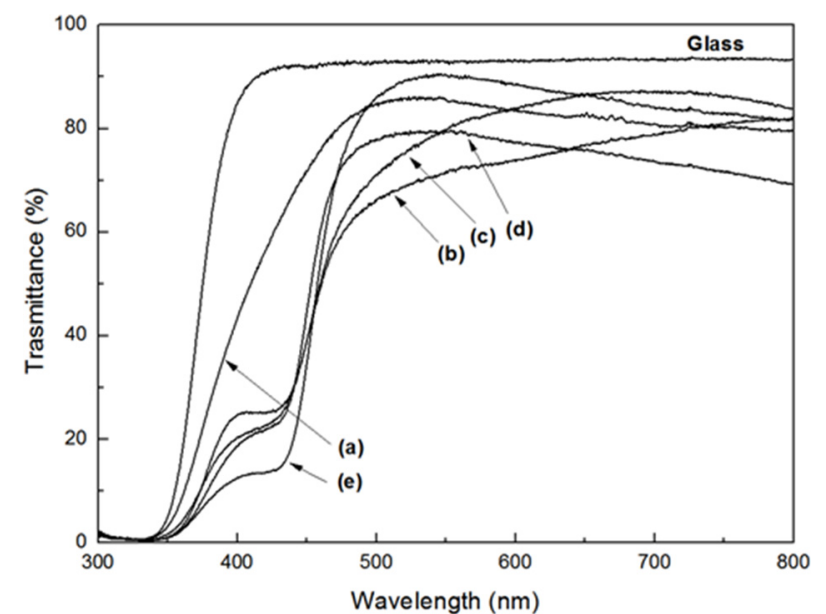

Fig. 3. Visible transmittance of $\mathrm{ZnO}, \mathrm{SnO}_{2}$ single layer and $\mathrm{ZnO} /$ $\mathrm{Ag} / \mathrm{SnO}_{2}$ tri-layer films. (a) $\mathrm{SnO}_{2} 100 \mathrm{~nm}$, (b) $\mathrm{ZnO} 30 \mathrm{~nm} / \mathrm{Ag} 10$ $\mathrm{nm} / \mathrm{SnO}_{2} 70 \mathrm{~nm}$, (c) $\mathrm{ZnO} 50 \mathrm{~nm} / \mathrm{Ag} 10 \mathrm{~nm} / \mathrm{SnO}_{2} 50 \mathrm{~nm}$, (d) $\mathrm{ZnO} 70$ $\mathrm{nm} / \mathrm{Ag} 10 \mathrm{~nm} / \mathrm{SnO}_{2} 30 \mathrm{~nm}$, (e) $\mathrm{ZnO} 100 \mathrm{~nm}$.

보다는 낮지만, 실온 증착조건 을 고려하면 표시소자의 투 명전극 재료로서의 가능성은 충분하다고 사료된다. 최근 D. R. Sahu[7]가 보고한 것과 같이, Oxide/ $\mathrm{Ag} /$ oxide 적층박막 에서 $\mathrm{Ag}$ 층간막은 입사광에 대한 반사거울 효과를 보이며 상부 Oxide 박막은 반사방지막 역할을 하기 때문에 $10 \mathrm{~nm}$ 두께의 $\mathrm{Ag}$ 금속층이 삽입되었어도 $\mathrm{ZnO}$ 및 $\mathrm{SnO}_{2}$ 단층박막의 가시광투과율에 근접하는 결과를 나타낸 것으 로 사료된다.

표 3 에 $\mathrm{ZnO}, \mathrm{SnO}_{2}$ 단층박막과 $\mathrm{ZnO} / \mathrm{Ag} / \mathrm{SnO}_{2}$ 적층박막
Table 3. Electrical properties of the $\mathrm{ZnO}, \mathrm{SnO}_{2}$ and $\mathrm{ZnO} / \mathrm{Ag} / \mathrm{SnO}_{2}$ (ZAS) thin films.

\begin{tabular}{cccc}
\hline $\begin{array}{c}\text { Thickness } \\
(\mathrm{nm})\end{array}$ & $\begin{array}{c}\text { Carrier density } \\
(\mathrm{cm}-3)\end{array}$ & $\begin{array}{c}\text { Mobility } \\
(\mathrm{cm} 2 / \mathrm{Vs})\end{array}$ & $\begin{array}{c}\text { Resistivity } \\
(\Omega \mathrm{cm})\end{array}$ \\
\hline $\mathrm{ZnO}, 100$ & $3.00 \times 10^{13}$ & 3.29 & $6.32 \times 10^{-4}$ \\
$\mathrm{SnO}_{2}, 100$ & $5.49 \times 10^{19}$ & 3.11 & $3.65 \times 10^{-2}$ \\
$\mathrm{ZAS}(30 / 10 / 70)$ & $9.58 \times 10^{21}$ & 6.15 & $1.06 \times 10^{-4}$ \\
$\mathrm{ZAS}(50 / 10 / 50)$ & $7.09 \times 10^{21}$ & 7.30 & $1.21 \times 10^{-4}$ \\
ZAS $(70 / 10 / 30)$ & $6.24 \times 10^{21}$ & 7.82 & $1.28 \times 10^{-4}$ \\
\hline
\end{tabular}

의 두께에 따른 박막의 전기적 특성변화를 나타내었다. $\mathrm{Ag}$ 박막이 삽입된 적층박막들이 급격히 낮아진 비저항을 보였 으며, $\mathrm{ZnO} 30 \mathrm{~nm} / \mathrm{Ag} 10 \mathrm{~nm} / \mathrm{SnO}_{2} 70 \mathrm{~nm}$ 박막이 가장 낮은 $6.83 \times 10^{-5} \Omega \mathrm{cm}$ 의 비저항을 보였다. 표 2 와 같이 상 부 $\mathrm{SnO}_{2}$ 박막이 두꺼워 질수록 전하밀도가 증가함으로써 전기비저항 감소에 효과적으로 기여함을 알 수 있었다.

표 4에 $\mathrm{ZnO}, \mathrm{SnO}_{2}$ 단층박막과 $\mathrm{ZnO} / \mathrm{Ag} / \mathrm{SnO}_{2}$ 적층박막 의 두께에 따른 Figure of merit(FOM) 수치변화를 나타 내었다. FOM 수치는 투명전도성 소재의 전기적 및 광학 적 물성을 비교할 수 있는 척도로서, 가시광투과도와 전기 전도도는 서로 반비례 관계를 가지며 관계식은 아래와 같 다 [8].

Figure of merit $=\mathrm{T}^{10} / \mathrm{R}_{\mathrm{sh}}$

위 관계식에서 $\mathrm{T}$ 는 가시광투과도이며 $\mathrm{R}_{\mathrm{sh}}$ 는 면저항을 나 타낸다. 본 연구에서 면저항이 가장 높은 $\mathrm{ZnO}$ 박막의 
Table 4. Figure of merit (FOM) of the $\mathrm{ZnO}, \mathrm{SnO}_{2}$ single layer and $\mathrm{ZnO} / \mathrm{Ag} / \mathrm{SnO}_{2}$ tri-layer films.

\begin{tabular}{cccc}
\hline $\begin{array}{c}\text { Thickness } \\
(\mathrm{nm})\end{array}$ & $\begin{array}{c}\text { Optical } \\
\text { Transmittance } \\
(\%)\end{array}$ & $\begin{array}{c}\text { Sheet } \\
\text { Resistance } \\
(\Omega / \square)\end{array}$ & FOM $(\Omega-1)$ \\
\hline $\mathrm{ZnO}, 100$ & 83.7 & $5.6 \times 10^{9}$ & $2.95 \times 10^{-11}$ \\
$\mathrm{SnO}_{2}, 100$ & 81.8 & $3.3 \times 10^{3}$ & $4.06 \times 10^{-5}$ \\
$\mathrm{ZAS}(30 / 10 / 70)$ & 74.8 & 9.64 & $5.69 \times 10^{-3}$ \\
ZAS $(50 / 10 / 50)$ & 80.8 & 11.0 & $1.08 \times 10^{-2}$ \\
ZAS $(70 / 10 / 30)$ & 73.7 & 11.64 & $4.06 \times 10^{-3}$ \\
\hline
\end{tabular}

FOM 수치가 $2.95 \times 10^{-11} \Omega^{-1}$ 이었으며, $\mathrm{SnO}_{2}$ 박막의 $\mathrm{FOM}$ 수치는 $4.06 \times 10^{-5} \Omega^{-1}$ 으로 증가하였다. $10 \mathrm{~nm}$ 두 께의 $\mathrm{Ag}$ 층간막 을 적용한 $\mathrm{ZnO} / \mathrm{Ag} / \mathrm{SnO}_{2}$ 박막의 면저항 은 $\mathrm{Sn}$ 두께에 반비례하며 감소하여 $\mathrm{FOM}$ 수치는 증가하 였으나, 가시광투과율을 고려한 결과로서 $\mathrm{ZnO} 50 \mathrm{~nm} / \mathrm{Ag}$ $10 \mathrm{~nm} / \mathrm{SnO}_{2} 50 \mathrm{~nm}$ 박막이 상대적으로 전기광학적 완성도 가 우수한 $1.08 \times 10^{-2} \Omega^{-1}$ 의 $\mathrm{FOM}$ 수치를 보임으로서 효과 적인 적층구조임을 알 수 있었다.

\section{4. 결 론}

본 연구에서는 RF와 DC 마그네트론 스퍼터를 이용하여 유리기판에 $\mathrm{ZnO}$ 와 $\mathrm{SnO}_{2}$ 단층박막과 $\mathrm{ZnO} / \mathrm{Ag} / \mathrm{SnO}_{2}$ 적층 박막을 증착하고 두께변화에 따른 전기적, 광학적 특성을 분석하여 이상적인 $\mathrm{ZnO} / \mathrm{Ag} / \mathrm{SnO}_{2}$ 적층구조를 고찰하였다.

$\mathrm{X}$ 선회절과 원자간력현미경 분석을 통하여 $\mathrm{ZnO}$ 박막의 두께에 비례하여 결정립 크기와 표면거칠기가 증가함을 알 수 있었으며, 가시광투과도는 $\mathrm{ZnO}$ 와 $\mathrm{SnO}_{2}$ 박막이 상대적 으로 우수하였으나, $\mathrm{ZnO} 50 \mathrm{~nm} / \mathrm{Ag} 10 \mathrm{~nm} / \mathrm{SnO}_{2} 50 \mathrm{~nm}$ 적층박막 또한 $\mathrm{Ag}$ 중간층의 반사거울 효과로 $80.8 \%$ 의 가
시광 투과율을 보였다.

$\mathrm{ZnO} / \mathrm{Ag} / \mathrm{SnO}_{2}$ 적층박막의 두께변화에 따른 전기광학적 완성도(Figure of merit) 를 비교한 결과, $\mathrm{ZnO} 50 \mathrm{~nm} / \mathrm{Ag}$ $10 \mathrm{~nm} / \mathrm{SnO}_{2} 50 \mathrm{~nm}$ 박막이 가장 높은 $1.08 \times 10^{-2} \Omega^{-1}$ 의 $\mathrm{FOM}$ 을 보임으로써, 경량성과 유연성을 갖는 플렉시블 투 명전극재로 $\mathrm{Ag}$ 중간층을 채용한 $\mathrm{ZnO} 50 \mathrm{~nm} / \mathrm{Ag} 10 \mathrm{~nm} /$ $\mathrm{SnO}_{2} 50 \mathrm{~nm}$ 적층박막이 유용함을 알 수 있었다.

\section{ACKNOWLEDGEMENT}

This work was supported by the 2018 Research Fund of University of Ulsan.

\section{REFERENCES}

1. S. B. Koo, C. M. Lee, S. J. Kwon, J. M. Jeon, J. Y. Hur, and H. K. Lee, Met. Mater. Int. 25, 117 (2019).

2. H. S. Kim and S. J .Kim, Korean J. Met. Mater. 57, 84 (2019).

3. C. H. Cheng and J. M. Ting, Thin Solid Films 516, 203 (2007).

4. S. Kim, S. K. Kim, S. Y. Kim, S. B. Heo, D. Choi, D. Son, and D. Kim, J. Korean. Soc. Heat Treat. 26, 288 (2013).

5. S. Kim, S. H. Kim, S. Y Kim, J. Jeon, T. Gong, D. Choi, D. Son, and D. Kim, Ceram. Int. 40, 6673 (2014).

6. Y. Song, T. Eom, S. Heo, and D. Kim, J. Korean. Soc. Heat Treat. 29, 151 (2016).

7. D. R. Sahu, S. Y. Lin, and J. L. Huang, Appl. Surf. Sci. 252, 7509 (2006).

8. G. Haacke, J. Appl. Phys. 47, 4086 (1976). 